\title{
Advanced cancer: aiming for the best in care
}

\author{
Irene Higginson
}

Cancer is a common disease; it affects about one in three people, and eventually $27 \%$ of men and $24 \%$ of women will die of it. ${ }^{1}$ Many different professionals, in hospital and in the community, may be involved in the care of a person with advanced cancer. They include general practitioners; hospital staff such as general physicians, oncologists, surgeons, specialists in palliative medicine and medicine for elderly people, and nurses; community nurses; social workers; physiotherapists; and, in some cases, psychiatrists.

This paper deals with the effectiveness, humanity, and equity of care of patients with advanced cancer and considers mechanisms to improve care. Prevention and treatment aimed at curing cancer are not included.

\section{Quality of care of individual patients} ASSESSMENT

Assessment is the systematic gathering of information to identify needs and problems and then to plan future care. ${ }^{2}$ To ensure quality for patients with advanced cancer, assessment is the first essential key step. Problems are complex and often change. For example, in a study of pain in 100 patients with cancer Twycross and Fairfield found 303 different types of pain; 80 patients had more than one type of pain, and 34 had four different types of pain or more. Cancer was the cause of only $63 \%$ of the pains; muscle pains, pains due to constipation, and arthritic pains were also common. ${ }^{3}$ Detailed assessment is important to determine the aetiology of the cancer and thereby the treatment of symptoms and the prognosis. ${ }^{4}$ Equally, emotional, psychological, spiritual, and social circumstances and problems require assessment.

One means of assisting assessment is to use a checklist of important aspects. Documentation standards of general care, referral details, admission assessment, and progress have been developed and used to audit care. ${ }^{5}$ In some instances checklists for individual aspects of care, such as giving information, have been produced as a result of audits in general practice ${ }^{6}$ or other settings. ${ }^{7}$ In an audit of palliative care support teams in the south-east of England a 17 item schedule - the support team assessment schedule - was developed to reflect the possible outcomes of palliative care. ${ }^{8}$ However, its range of key problems provided staff with a checklist to assist their assessment of patients and families. It included symptoms, emotional and psychological needs, communication, planning future care, and aspects of home care, such as practical and financial needs, all of which staff wanted to address in their day to day care.
CONTROL OF PAIN AND OTHER SYMPTOMS

Unpleasant and distressing symptoms, especially pain, are a common problem for patients with cancer in the last year of life, and the control of such symptoms was one of the first goals of the palliative care movement in the 1970s. ${ }^{910}$ Pain has physical, emotional, spiritual, and social components. The use of pain diaries ${ }^{11}$ or pain charts ${ }^{3}$ can help in assessing and monitoring pain. The World Health Organisation made three recommendations on the use of analgesics for pain responsive to opioids (for example, morphine). The first is "by the mouth," the preferred route, and by continuous subcutaneous injection if this is not possible. The second is "by the clock," regular doses as recommended, which for most liquid forms of morphine is four hourly. The third is "by the ladder," increasing the potency of drugs, progressing from non-opioids to weak opioid, to strong opioid. ${ }^{12}$ Not all pains respond to opioids; adjuvant analgesics are needed if pain is due to bone destruction (a non-steroidal anti-inflammatory drug) or nerve destruction (an antidepressant or anticonvulsant). Nerve blocks and epidural analgesics can now often be used to control some types of pains, and they have the advantage of not causing drowsiness. ${ }^{13}$

Symptoms such as dyspnoea, nausea and vomiting, and weakness are also complex and difficult to control. ${ }^{14-16}$ There are now clinical algorithms describing step by step assesssment and management of symptoms, plus many textbooks dedicated to control of symptoms. ${ }^{13}$ 17-19

\section{PSYCHOLOGICAL PROBLEMS}

Between $30 \%$ and $40 \%$ of people with cancer experience periods of depression or anxiety, or both. ${ }^{20}$ Increased distress often occurs at specific points - for example, at diagnosis and during the terminal period ${ }^{21}$ - but problems are often missed by staff. ${ }^{22}$ Research has shown that if these problems are recognised and the patient referred appropriately the emotional distress can be reduced and adaptation enhanced. ${ }^{24}$ This could be achieved by nurses or other staff caring for the patient. Psychological care is stressful for all staff, ${ }^{25}$ and support for staff is often needed.

CARE OF THE FAMILY

A diagnosis of cancer reverberates through the family, causing it to adapt and adjust. ${ }^{2}$ When cancer is advanced the family is faced with multiple problems, including the practicalities and stresses of caring for the patient at home or visiting them elsewhere, emotional distress, 
fatigue, and grief. Different family members are affected differently. The hospice philosophy considers the patient and family as "a unit of care," and many aspects, such as psychological needs, communication, information, and practical support, are equally important for the family as for the patient. Care for the family also needs to continue into the bereavement period, although the optimal support for bereaved family members is not yet known. Gilley described a "dying triad" in which the family need to be "emotionally held" during the nurturing of a dying patient. ${ }^{26}$ However, there is evidence that hospital based care is less successful than community care in assessing the needs of the family, ${ }^{23}$ and despite the intervention of palliative support teams family anxiety is often very severe at the time of the patient's death. ${ }^{8}$ Further research is needed to identify the optimal methods of supporting the family.

\section{INFORMATION AND COMMUNICATION}

Consistent information regarding the disease, choice of treatment, and prognosis for individuals is crucial, because cancer has such a major impact on future life. ${ }^{27}$ Information relieves anxiety and reduces pain and side effects from treatment, enhancing the person's ability to cope with illness. ${ }^{28}$ Patients and families are often unaware of available services and what these can offer, and in some areas so are professionals. Hospices and palliative services often help others by providing information on local services.

Poor communication from doctors and nurses continues to be a frequent problem experienced by patients, family members or friends, and professionals. In a study of 65 patients with advanced cancer $25 \%$ of patients and $26 \%$ of family members spontaneously reported poor communication from hospital doctors and nurses, especially at the time of diagnosis. ${ }^{29}$ Failure of communication was the most common problem identified by both bereaved relatives and general practitioners in one inner city general practice audit of recent deaths. ${ }^{6}$

Effective communication is difficult. Maguire and Faulkner suggest ways of dealing with difficulties of breaking bad news, establishing and identifying concerns, and handling difficult questions such as: "Is this cancer?" $30{ }^{31}$ Handling uncertainty is difficult in late stage illness. When asked: "How long have I got?" it is tempting to give a finite answer or a range of time. However, such predictions are usually inaccurate, tend to err on the optimistic side,,$^{30}$ and cause problems for patients and families if they are wrong. Maguire and Faulkner propose that staff should acknowledge their uncertainty and provide information, if desired, on the signs and symptoms that would herald a deterioration. ${ }^{31}$ Collusion, when patients and their families withhold the truth from each other, may result from an act of love where one party cannot bear to cause anguish to their loved one. However, this has very high emotional costs for the family members and places a great strain on their relationship. ${ }^{31}$

\section{COORDINATION}

Communication is needed between all professional staff caring for a patient with advanced cancer to ensure liaison and to prevent duplication or delay. Poor coordination whereby professionals did not know each other's actions, especially poor coordination between the hospital and community or delays because of poor coordination, was a problem for $17 \%$ of patients and $11 \%$ of family members in one London study. ${ }^{29}$

NEED TO PLAN, LAST EVENTS, APPROPRIATE DYING

Weisman defined "appropriate death" as "absence of suffering, preservation of important relationships, an interval for anticipatory grief, relief of remaining conflicts, belief in timeliness, exercise of feasible options and activities, and consistency with physical limitations, all within the scope of one's ego ideal." ${ }^{32}$ Kellehear described the features of the modern "good death" as awareness of dying, social adjustments and personal preparations, public preparations (legal, financial, religious, funeral, medical), work or activities reduced, and farewells. ${ }^{33}$ The earlier parts of these definitions have been covered, but the later aspects are often overlooked and yet are important to the humanity of care. Open discussion can help patients to plan meetings, events, or even to write their will before their death. Some people have no wish to do this, but for others it is important to plan a special holiday or the details of their funeral service.

SPIRITUAL NEEDS

A holistic approach to care implies care for the body, mind and spirit. ${ }^{34}$ In many cases the word "spiritual" is equated or used synonymously with institutionalised religion. However, it is more appropriate to define this word in broader terms to include philosophical orientations to belief and meaning in life. Spiritual needs and problems have been categorised for nurses in terms of spiritual pain, alienation, anxiety, guilt, anger, loss, and despair. ${ }^{34}$ The support team assessment schedule includes a spiritual component but in a simple form, assessing whether or not the person is experiencing a crisis of faith or beliefs, whatever his or her beliefs may be. ${ }^{8}$ More detailed assessments of spiritual needs are required for some patients and families.

DIGNITY

In the care of people with advanced disease the objective is that they should "live" until they die, not merely exist. ${ }^{17}$ The aspects already described are all important to achieving dignity. The addition of personal possessions and clothing, regular visitors, privacy when required, and personal care of appearance, such as hairdressing, etc, are all important to dignity ${ }^{35}$ and become most at risk 
for inpatients. Many hospices now offer various arts activities, some in which patients participate, such as painting, craft work, and poetry, and others in which patients observe, such as performances of music or ballet. ${ }^{36} 37$ These activities can improve patients' self esteem, give them new dimensions, and in some cases help them to explore their own emotions. ${ }^{37} 38$

\section{Access to care and equity}

A range of services are usually offered for a person with advanced cancer, including hospital care, day care, care from the general practitioner, district nursing, hospice and support team or home care teams (or Macmillan nurses). Other community staff, such as occupational therapy, physiotherapy, and chiropody staff, are often needed.

Cartwright and Seale's study in 1988 of the last year of life, gives insight into the equity of care for people who are dying, hitherto largely ignored. This national survey was based on a random sample of 639 deaths in adults (aged 15 years or more) that were registered in England. ${ }^{39}$ Interviewers tried to contact the person who could tell them most about the last 12 months of life of the deceased. Only a small proportion $-7 \%$ of those who died received some form of hospice care $(25 \%$ of cancer deaths) either as an inpatient or from a support team, or both. ${ }^{40}$ These patients were reported to have had better pain relief and a greater awareness of their diagnosis and prognosis, and they were more satisfied with the services they received. ${ }^{40} 41$

However, the characteristics of patients receiving hospice care may have been different. For example, there were social class differences: more middle class people had been in private hospitals and hospices than working class people $(7 \% v 1 \%)^{42}$; the middle class people died at an older age and were reported to have had a better quality of life before death. Cartwright concluded that "money and class contribute to the quality of life before death, as well as postponing death." 42

In another study the referral rate per 100 district cancer deaths to five support teams in the south-east of England was between 23 and $31 .^{23}$ Barnett and McCarthy attempted to describe the needs of patients who were not referred to a London support team. Data from national and local cancer registries proved very unreliable but did identify some patients who were in severe difficulties and who were not receiving care. In cases of cancer identified by local general practitioners the patients tended to be in much better circumstances and not in need of extra care by the support team. ${ }^{43}$

Little is known about the quality of care of elderly patients with cancer and patients from minority ethnic groups. Patients referred to hospices and specialist palliative care services tend to be younger than those who are not referred at all..$^{23} 4041$ If a referral is made, there is some evidence that those who receive home palliative care are younger than those who receive inpatient hospice care. ${ }^{44}$ The effect of cancer and its treatment on quality of life and survival in older patients needs to be established. ${ }^{45}$

Most hospices receive only few referrals of patients from ethnic minorities. The rate of such referrals has rarely been studied, although one hospice in Cardiff reported receiving only $1 \%$ of patients from ethnic minorities, although $4.3 \%$ of people in the city were from ethnic minorities. ${ }^{46} \mathrm{~A}$ case report outlining the difficulties encountered while dealing with a Korean family demonstrated the many difficulties due to language and cultural differences and misdiagnosis. ${ }^{46}$ Guidelines are available for the care of people with different faiths. ${ }^{47}$

\section{Home care}

Studies in the United Kingdom have shown that patients would prefer to be cared for at home if possible. ${ }^{48}$ In the United States, however, bereaved relatives were more satisfied with inpatient hospice care compared with hospital and community care; they also identified fewer unmet needs. ${ }^{49}$ The American study was not randomised so the samples may have been biased; community services in these two countries are also very different, which suggests that these findings are not directly applicable to the United Kingdom. Nevertheless, more work is needed to determine patients' preferences and whether they are met. Support teams have identified that the patient and families often need practical equipment and support in the home and require help in seeking financial benefits. ${ }^{23}$ These needs can determine whether a patient is able to remain at home. A positive finding from an audit of general practice showed that family members valued the general practitioner honouring their wishes for a patient to die at home and visiting the patient in hospital. ${ }^{6}$

\section{Mechanisms of improving quality}

STANDARDS, AUDITS, AND CONTRACTING

The table gives details of some of the standards and audit measures now available for the care of patients with advanced cancer. In 1991 the National Association of Health Authorities and Trusts published 10 standards that might be used by purchasers and providers when setting contracts for the care of people with a terminal illness (see table). ${ }^{35}$ The document also includes standards of care in nursing homes. More recently, the National Council for Hospice and Palliative Care Services published guidelines for health authorities and social services departments on care in the community for people who are terminally ill. ${ }^{54}$

Butland has argued that a major weakness of the existing contract for general practitioners is the total lack of any quality standards in their contracting system. ${ }^{55}$ Within the rest of the NHS quality is becoming a key element in the contracting process, with both purchasers and providers actively engaged in determining and monitoring standards. There is no equivalent in the general practice 
Some standards, audits, and checklists for care of patients with advanced cancer

\begin{tabular}{|c|c|c|}
\hline Name and source & Content & Setting \\
\hline $\begin{array}{l}\text { Care of people with a terminal } \\
\text { illness } \\
\text { National Association of Health } \\
\text { Authorities and Trusts }\end{array}$ & $\begin{array}{l}10 \text { Standards and responsibilities for contracts covering } \\
\text { policies, provision, consumer participation, education, direct } \\
\text { care, attitude, skills, and mix of staff, checklist } \\
\text { Standards of adequacy in nursing homes providing for people } \\
\text { who are terminally ill, covering dignity, staffing, furniture and } \\
\text { equipment, social needs, etc }\end{array}$ & $\begin{array}{l}\text { Purchasers and } \\
\text { providers of care }\end{array}$ \\
\hline $\begin{array}{l}\text { Standards of care: cancer } \\
\text { nursing } \\
\text { RCN Standards of Care } \\
\text { Project. Standards of care for } \\
\text { cancer nursing }\end{array}$ & $\begin{array}{l}13 \text { Topics covered: assessment, informational care, family } \\
\text { care, psychological support, coping and adaptation, } \\
\text { continuity of nursing care, primary prevention, secondary } \\
\text { prevention, cytotoxic chemotherapy, radiotherapy, altered } \\
\text { body image, pain, dying }\end{array}$ & $\begin{array}{l}\text { Nurses, providers of } \\
\text { care }\end{array}$ \\
\hline $\begin{array}{l}\text { Quality, standards, } \\
\text { organisational and clinical } \\
\text { audit for hospice and palliative } \\
\text { care services } \\
\text { National Council for Hospice } \\
\text { and Specialist Palliative Care } \\
\text { Services }\end{array}$ & $\begin{array}{l}\text { Review of quality needed in palliative care, potential benefits, } \\
\text { measures, and audit instruments and standards. Includes } \\
\text { brief description of eight audits or standards and examples or } \\
\text { measures used }\end{array}$ & $\begin{array}{l}\text { Palliative services, } \\
\text { purchasers and } \\
\text { providers of care }\end{array}$ \\
\hline $\begin{array}{l}\text { Support team assessment } \\
\text { schedule (STAS) } \\
\text { Higginson et al }{ }^{8} \text { Higginson }^{23}\end{array}$ & $\begin{array}{l}17 \text { Items which can be used as a checklist or for clinical } \\
\text { audit, covering: } \\
\text { Pain and symptoms (2) } \\
\text { Patient anxiety, insight, and spiritual needs (3) } \\
\text { Family anxiety and insight (2) } \\
\text { Planning affairs (2) } \\
\text { Communication (3) } \\
\text { Home services (3) } \\
\text { Support of other professionals (2) }\end{array}$ & $\begin{array}{l}\text { Community support } \\
\text { teams. But now } \\
\text { adapted to a core } 9 \\
\text { items for inpatient or } \\
\text { community care }\end{array}$ \\
\hline $\begin{array}{l}\text { Palliative care: guidelines for } \\
\text { good practice and audit } \\
\text { measures } \\
\text { Working Group of the Royal } \\
\text { College of Physicians }\end{array}$ & $\begin{array}{l}29 \text { Items for clinical audit covering: } \\
\text { Admission policy (5) } \\
\text { Clinical management (6) } \\
\text { Support of patient and family (5) } \\
\text { Communication (4) } \\
\text { Documentation and administration (9) }\end{array}$ & Inpatient hospices \\
\hline $\begin{array}{l}\text { Palliative care core standards } \\
\text { Trent Hospice Audit Group }\end{array}$ & $\begin{array}{l}6 \text { Standard statements with } 56 \text { process and outcome items: } \\
\text { Collaboration with other agencies (8) } \\
\text { Symptom control (6) } \\
\text { Patient/carer information (9) } \\
\text { Emotional support (11) } \\
\text { Bereavement care and support (13) } \\
\text { Specialist education/training for staff (9) }\end{array}$ & $\begin{array}{l}\text { Inpatient hospice and } \\
\text { community teams }\end{array}$ \\
\hline $\begin{array}{l}\text { Good practice in terminal care } \\
\text { Harper et } a l^{33}\end{array}$ & $\begin{array}{l}158 \text { Propositions tested as standards covering administration; } \\
\text { staffing; facilities and their design; referral, admission and } \\
\text { discharge policies; nursing, communication, social work, } \\
\text { counselling, good practice, staff support, education }\end{array}$ & $\begin{array}{l}\text { Inpatient and day } \\
\text { hospices }\end{array}$ \\
\hline
\end{tabular}

contract, ${ }^{55}$ and there is concern about the quality of care offered. Cartwright found that fewer general practitioners visited dying patients at home in 1987 than 20 years previously. ${ }^{56}$ Although some patients were pleased with the service, others had experienced difficulties and criticised general practitioners' knowledge of pain control. ${ }^{57}$

The Royal College of Nursing standards of care project has developed structure, process, and outcome standards for 13 aspects of cancer nursing including information, family care, radiotherapy, cytotoxic chemotherapy, and pain (see table). ${ }^{2}$ Other clinical audits for patients with advanced disease are shown in the table.

\section{EDUCATION, TRAINING, AND FUTURE DEVELOPMENTS}

Practitioners have identified education needs to achieve symptom control and patient and family support. ${ }^{58}$ There are now opportunities for workshops and training in a whole variety of aspects of care of advanced cancer. St Christopher's Hospice in Sydenham, London, runs regular training for doctors, nurses, and other staff in symptom control and care for people with advanced cancer, and workshops on communication skills are available. In the United Kingdom the role of hospices and palliative support teams in supporting, advising, and educating other professionals has been emphasised. ${ }^{59} 60$ Many training manuals and programmes are available - for example, an interactive video developed by Marie Curie Cancer Care, London, and HELP (Helpful Essential Links to Palliative care), a problem based resource text for hospital doctors and other professionals, produced by the Cancer Relief Macmillan Fund, London. Both these organisations and other charities such as Help the Hospices offer a wide variety of training materials and courses.

The Royal College of General Practitioners and the Cancer Relief Macmillan Fund have recently established a facilitator in palliative care project in which an experienced general practitioner works with primary health care teams to help mobilise existing professional skills. ${ }^{61}$ There is also a diploma course in palliative medicine, based in Cardiff, and a diploma course in psychosocial palliative care, run from Southampton, for professionals who wish to train further in caring for patients with advanced disease.

Much is known about what affects the quality of care for patients with advanced cancer, and a range of standards, audits, and training material and packages are available. The challenge now is to put the knowledge into practice and use these tools to monitor and improve the quality of care for these patients. 
1 Department of Health. On the state of the public health for the vear 1990. London: HMSO, 1991.

2 RCN Standards of Care Project. Standards of care for cancer nursing. London:

3 Twycross RG, Fairfield $\mathrm{S}$. Pain in far advanced cancer. Pain 1982;14:303-10.

4 Bruera E, MacMillan K, Hanson J, MacDonald RN. The Edmonton staging sysem for cancer pain: preliminary report. Pain 1987;37:203-9.

5 Caterall RA. Methods of audit: regional documentation standards. In: Higginson I, ed. Clinical audit in palliative care. Oxford: Radcliffe Medical Press (in press).

6 Berlin A, Spencer JA, Bhopal RS, van Zwanenberg TD. Audit of the deaths in general practice: a pilot study of the critical incident technique.Quality in Health Care $1992 ; 1: 231-5$

7 Finlay I. Audit experience: views of a hospice director. In: Higginson I, ed. Clinical audit in palliative care. Oxford Radcliffe Medical Press (in press)

8 Higginson I, Wade A, McCarthy M. Effectiveness of two palliative support teams. F Public Health Med 1992; 14:50-6.

9 Saunders CM. The management of terminal disease. London: Edward Arnold, 1978

10 Parkes CM. Terminal care: evaluation of inpatient service at St Christopher's Hospice. Part I. Views of surviving spouse on effects of the service on the patient. Postgrad Med f 1979;55:517-22

11 Raiman J. Monitoring pain at home. Foumal of District Nursing 1986;4:4-6.

12 World Health Organisation. Cancer pain relief. Geneva: WHO, 1986

13 Twycross RG, Lack SA. Symptom control in far advanced cancer: pain relief. London: Pitman, 1983.

14 Higginson I, McCarthy M. Measuring symptoms in terminal cancer: are pain and dyspnoea controlled? $f R$ Soc Med 1989;82:1761-4.

15 Regnard C, Ahmedzai S. Dyspnoea in advanced cancer - a flow diagram. Palliative Medicine 1990;4: $311-5$.

16 Krech RL, Davis J, Walsh D, Curtis EB. Symptoms of lung cancer. Palliative Medicine 1992;6:309-15.

17 Hanratty JF. Palliative care of the terminally ill. Oxford: Radcliffe Medical Press, 1989.

18 Doyle D, Hanks GWC, MacDonald N, eds. Oxford textbook of palliative medicine. Oxford: Oxford University Press,

19 Twycross RG, Lack SA. Therapeutics in terminal cancer. 2nd ed. Edinburgh: Churchill Livingstone, 1990.

20 Derogatis LR, Morrow GR, Fetting J, Penman D, Piasetsky $\mathrm{S}$, Schmale AM, et al. The prevalence of psychiatric disorders among cancer patients. $\mathcal{F} A M A$ 1983;249: 751-57.

21 Silberfarb PM, Maurer LH, Crouthamel CS. Psychosocial aspects of neoplastic disease. Functional status of breast cancer patients during different treatment regimes. $A m \mathcal{F}$ Psychiatry 1980;137:450-5.

22 Maguire P. Monitoring the quality of life in cancer patients and their relatives. In: Symington T, Williams AE, McVie JG, eds. Cancer: assessment and monitoring. London: JG, eds. Cancer: assessment and
Churchill Livingstone, 1980: 40-52.

23 Higginson I. The development, validation, reliability and practicality of a new measure of palliative care: the Support Team Assessment Schedule [PhD Thesis]. London: University of London, 1992: pp 309.

24 Maguire P, Tait A, Brooke M, Thomas C, Sellwood R. Effect of counselling on the psychiatric morbidity associated with mastectomy. BMF 1980;281:1454-6.

25 Wilkinson S. The reality of nursing cancer patients. Lampada 1987;12:12-9.

26 Gilley S. Intimacy and terminal care. $f R$ Coll Gen Practice 1988;38:121-2.

27 Moorey S. The psychological impact of cancer. In: Webb P, ed. Oncology for nurses and health care professionals. London: Harper and Row, 1988:14-35.

28 Ridgeway V, Matthews A. Psychological preparation for surgery: a comparison of methods. B 7 Clin Psychol surgery: a compa

29 Higginson I, Wade A, McCarthy M. Palliative care: views of patients and their families. BMF 1990;301: views of

30 Maguire $P$, Faulkner A. Communicating with cancer patients. I. Handling bad news and difficult questions. BMF 1988;297:907-9.

31 Maguire P, Faulkner A. Communicating with cancer patients. II. Handling uncertainty, collusion, and denial. BMF 1988;297:972-4.
32 Weisman $\mathrm{AD}$. The psychiatrist and the inexorable. In Feifel IC, ed. New meanings of death. New York: McGraw-Hill, 1977.

33 Kellehear A Dying of cancer. The final vear of life. London: Harwood, 1990

34 Laburn E. Spiritual care: an element in nursing care planning. $\mathcal{f}$ Adv Nursing 1988;13:314 -20.

35 National Association of Health Authorities and Trusts. Care of people with a terminal illness. Birmingham NAHAT, 1991

36 Frampton $\mathrm{D}$. Restoring creativity to the dying patient. $B M Y$ 1986;293:1593-5.

37 Frampton D. Arts activities in the United Kingdom hospices. F Palliat Care 1989;5(4):25-34.

38 Higginson I. Description and preliminary evaluation of the Chelmsford Hospice arts project. Report to Hospice Art London. London: Department of Epidemiology and Public Health, University College London, 1991

39 Cartwright A, Seale C. The natural history of a survey: an account of the methodological issues encountered in a study of life before death. London: King's Fund, 1990

40 Seale C. Death from cancer and death from other causes: the relevance of the hospice approach. Palliatice Medicine 1991:5:12-9.

41 Seale C. A comparison of hospice and conventional care. Soc Sci Med 1991;31:147-52.

42 Cartwright A. Social class differences in health and care in the year before death. I Epidemiol Community. Health $1992 ; 46: 81-7$.

43 Barnett $M$, McCarthy $M$. Identification of terminally-ill patients in the community. In: Doyle D, ed. 1986 International symposium on pain control. London: Royal Society of Medicine, 1987: 78-80. (International Symposium Series No 123.)

44 Dunphy K, Amesbury B. A comparison of hospice and home care patients: patterns of referral, patient characteristics and place of death. Palliative Medicin 1991;4:105-11.

45 Balducci L, Andes T, Carbone PP, Friedman M, Fulmer T, Galakotos A, et al. Issues in treatment. Cancer

46 Clarke M, Finlay I, Campbell I. Cultural boundaries in care. Palliative Medicine 1991;5:63-5.

47 Neuberger J. Caring for dying people of different faiths. London: Lisa Sainsbury Foundation, 1987

48 Townsend J, Frank AO, Fermont D, Dyer S, Karran O, Walgrove A, et al. Terminal cancer care and patients preference for place of death: a prospective study. $B M Y$ 1990;301:415-7.

49 Dawson NJ. Need satsifaction in terminal care settings. So Sci Med 1991;32:83-7.

50 National Council for Hospice and Specialist Palliative Care Services. Quality, standards, organisational and clinical audit for hospice and palliative care services. London: National Council for Hospice and Specialist Palliative Care Services, 1992.

51 Working Group of the Research Unit, Royal College of Physicians. Palliative care: guidelines for good practice and audit measures. F $R$ Coll Phys Lond 1991;25:325-8.

52 Trent Hospice Audit Group. Palliative care core standards. a multidisciplinary approach. Derby: Nightingale

53 Harper R, Ward A, Westlake L, Williams BT. Good practice in terminal care. Some standards and guidelines for hospice inpatient units and day hospices. Sheffield: Department of Community Medicine, University of Sheffield, 1988.

54 National Council for Hospice and Specialist Palliative Care Services. Care in the community for people who ar terminally ill. Guidelines for health authorities and sociol services departments. London: National Council for Hospice and Specialist Palliative Care Services, 1993.

55 Butland $G$. The future of FHSAs: commissioning for quality. BMF 1993;306:251-2.

56 Cartwright $\mathrm{A}$. Changes in life and care in the year before death 1969-1987. F Public Health Med 1991;13:81-7.

57 Cartwright A. Balance of care for the dying between hospitals and the community: perceptions of general practitioners, hospital consultants, community nurses practitioners, hospital consultants, communit

58 Haines A, Booroff A. Terminal care at home: perspective from general practice. BMf 1986;292:1051-

59 Working Group on Terminal Care. National terminal car policy. F R Coll Gen Pract 1980;30:466-71

60 James N. A family and a team. In: Gilmore A, Gilmore S eds. A safer death: multidisciplinary aspects of terminal care. New York: Plenum, 1988:125-31.

61 Sandars J. Palliative care - the general practice challenge. fournal of Cancer Care 1993;2:2-5. 